\section{Urologia \\ Internationalis}

\section{Ammad A. Farooqi Shahzad Bhatti}

Institute of Molecular Biology and Biotechnology, University of Lahore, Lahore, Pakistan

\title{
Getting Personal with Prostate Cancer: Adding New Pieces to an Incomplete Jigsaw Puzzle
}

Key Words

Castration-resistant prostate cancer - Androgen

deprivation therapy

\section{Abstract}

Prostate cancer is a multifaceted molecular anomaly that is insurmountable to date because of the orchestrated network of negative regulators that drive carcinogenesis. A substantial fraction of information has been added that gives yet an unclear snapshot of therapeutic interventions in prostate cancer. Increasing sophisticated interpretations point towards some important aspects of prostate cancer aggressiveness like microRNAs, prostate cancer stem cells and TRAIL (tumor necrosis factor-related apoptosis-inducing ligand) refractoriness. In this review, we will evaluate the push and pull between oncomirs and tumor suppressors in tipping the scales of cancer. Furthermore, multicomponent rational drug designs with a claim to overcome stumbling blocks will be discussed. Translation of the outcomes achieved in the understanding of carcinogenesis at the patient's bedside is possibly the principal challenge in cancer research.

Copyright $\odot 2011$ S. Karger AG, Basel

\section{Introduction}

Prostate cancer encompasses a heterogeneous assembly of tumors, with distinctive risk factors, clinical presentation, histopathological features and molecular uniqueness. Currently, cure of metastatic or recurrent disease is dependent on conventional chemotherapy combination regimens. It is a matter of deep concern that efficient clinical management of prostate cancer has been relentlessly challenged by considerable intratumoral multiplicity at genomic and pathological levels and a limited understanding of the genetic elements governing disease development.

\section{Androgen Receptor Dynamics: 'Heads', It Wins, and 'Tails', Therapeutics Lose}

Neoplastic cells have to perpetuate the androgen receptor (AR)-mediated dynamics by a wide range of integrated pathways that crosstalk at various levels. It ensures the robust expression and activation of AR-mediated genes. There are multidirectional pathways opted for by the AR to meet the demands of a desperate cancer-prone environment. These pathways have been studied elsewhere $[1,2]$.

\section{KARGER}

Fax +41613061234 E-Mail karger@karger.ch www.karger.com
2011 S. Karger AG, Basel 0042-1138/11/0872-0127\$38.00/0 www.karger.com/uin
Ammad A. Farooq

IMBB (Institute of Molecular Biology and Biotechnology), University of Lahore

$1 \mathrm{Km}$ Thokar Niaz Baig, Raiwind Road

Lahore (Pakistan)

Tel.+92 332415 3787, E-Mail ammadahmad638@yahoo.com 


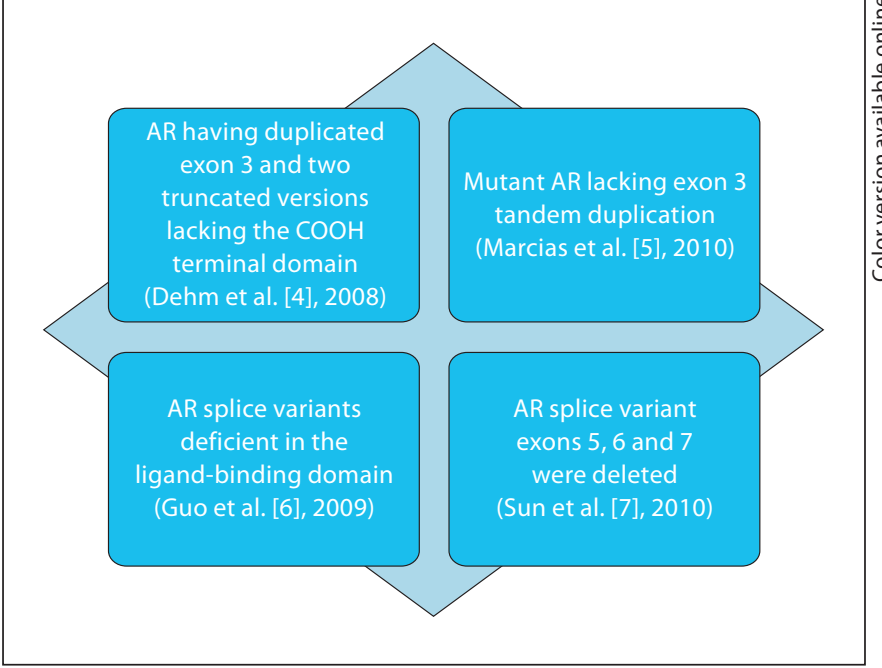

Fig. 1. AR variants documented by different research groups.

Li et al. [3] registered a robust expression of truncated $\mathrm{AR}$ isoforms in $22 \mathrm{Rv} 1$ cells along with intragenic reconstitution of an approximately 35-kb AR genomic segment harboring a cluster of alternative AR exons. Cloning of the break fusion junction in 22Rv1 cells displayed long interspersed nuclear elements (LINE-1) encompassing the rearranged segment and a microhomology-mediated break-induced replication. Henceforth, intragenic rearrangements have emerged as new mediators in cancer progression. Some other variants documented by other research groups are mentioned in figure 1 [4-7].

Arachidonic acid pathway members PLA2G7, HPGD, EPHX2 and CYP4F8 were identified as putative novel therapeutic targets in prostate cancer. EPHX2 and PLA2G7 correlated with AR and their inhibition reduced AR signaling. It is obvious that inhibition of these enzymes may be effective when combined with other treatments, such as androgen deprivation [8]. Lately, Kim et al. [9] have found that HOXB13 is a protein that is involved in suppression of AR-mediated signal transduction. This protein is downregulated in prostate carcinogenesis. Future research might converge upon mechanisms of restoration of the negative regulators of $A R$ signaling. There are some other proteins which coexist at the promoter region and are involved in activation of target genes. H2A.Z and ubiquitin-specific protease 10 are each required for transcriptional activation of the ARregulated prostate-specific antigen and KLK3 genes [10]. A combinatorial drug design seems to dampen the key regulators which augment disease progression. Pharma- cological targeting of STAT5 retards carcinogenesis because STAT5 cooperates with AR and favors cancer progression and aggressiveness [11]. Yang et al. [12] stated that HDAC4 enhances AR SUMOylation, raising the likelihood that deacetylase may act as an E3 ligase for AR SUMOylation. Knockdown of HDAC4 increases the activity of endogenous AR. Further studies are important to explore antineoplastic detailed mechanistic insights. Another tumor suppressor gene, BTG2, is downregulated in prostate cancer, and the re-establishment of this gene in BTG2-deficient cells has been shown to inhibit prostate cancer cell growth [13]. On a similar note, GLI1, important for Sonic hedgehog signal transduction, can act as a corepressor to considerably inhibit AR-mediated transactivation [14].

Tan et al. [15] stated that treatment of AR by dihydrotestosterone potently activated GRP78 expression, and there was a coexistence of GRP78 with Hsp70-Hsp90 client proteins. All these proteins limit the efficacy of drugs. A multipronged drug design is necessary to checkmate this group of negative regulators.

Accumulating data mark these AR variants as candidates for therapies directly targeting the AR rather than the ligand. Castration-resistant prostate cancer cells express variant ARs which included truncated ARs lacking the carboxyterminal ligand-binding domain, and small interfering RNA-mediated knockdown efficiently suppressed androgen-independent cell growth. Nigericinlike compounds suppress AR expression at the messenger RNA level. These could be applied as new-type therapeutic agents that inhibit a broad spectrum of AR variants in hormone-refractory prostate cancer [16]. However, there are some compensatory pathways which are switched on impairment of AR. Ablation of AR in in vitro cells induced PI3K-independent activation of Akt, which was triggered by calcium/calmodulin-dependent kinase II (CaMKII) [17, 18]. It has lately been found that grape seed extract potently inhibits histone acetyl transferase, leading to decreased AR-mediated transcription and cancer cell growth [19]. Similarly, procyanidin B3, an inhibitor of histone acetyltransferase, has broader implications in the inhibition of p300-dependent acetylation of ARs [20].

After having outlined the current approaches for treating prostate cancer, we now focus on emerging therapeutic opportunities for prostate cancer aggressiveness that are based on recent insights into molecular off-track activities of AR. Targeted therapeutics, particularly those that restrain the activity of ARs that are mutated and/or overexpressed in cancer, have revolutionized the treatment. Hsp90-based therapy has so far shown inadequate 
activity in the clinic. In accordance with the same interpretation, efficacy of a novel mitochondrial-targeted, small-molecule Hsp90 inhibitor, gamitrinib (GA mitochondrial matrix inhibitor), was evaluated by Kang et al. [21] in the Transgenic Adenocarcinoma of the Mouse Prostate model. They registered that gamitrinib has preclinical activity and favorable tolerability in a genetic model of localized and metastatic prostate cancer in immunocompetent mice. Another drug that has wider implications in blocking cancer activity is MDV3100; it blocks ligand receptor engagement and prevents nuclear shuttling of AR and coactivator recruitment of the ligand-receptor architecture [22].

There are an overwhelming number of trials done in an effort to put a stop to cancer aggressiveness, and therefore, one of the foremost goals in the future must be to 'bridge the gap between cancer research and effective therapies'.

\section{Twists and Turns on TRAIL to Therapy}

Tumor necrosis factor-related apoptosis-inducing ligand (TRAIL)-mediated therapy has emerged as a breakthrough in translational medicine; however, after accumulation of substantial information into the existing pool of therapeutic interventions, it is obvious that there is a refractoriness to TRAIL treatment.

KN-93 (a CaMKII inhibitor) has a broader effect on apoptosis than just inhibition of CaMKII: KN-93 also synergistically induces cell death in combination with low doses of doxorubicin and converts the phenotype of prostate cancer cells from TRAIL resistant to TRAIL sensitive. This is suggestive of the fact that KN-93 could be used for novel therapeutic approaches when hormonal therapy has failed [23]. TRAIL has been used in conjunction with a broad spectrum of phytonutrients, and results were positive in terms of sensitization of cells to TRAIL [24-26]. These nutraceuticals sensitize cells to TRAIL by upregulating death receptors. In prostate cancer, transforming growth factor (TGF) signal transduction has antineoplastic activities. These activities are attenuated by negative regulators of TGF signaling. We have shown that negative regulators of TGF transduction cascades, especially SMURF and NEDD4, are actively involved in downregulation of TRAIL and upregulation of cFLIP. cFLIP is believed to interfere with the initiation of an apoptotic response by TRAIL. Treatment of cells with TGF and depletion of SMURF and NEDD4 resulted in the upregulation of TRAIL and in the subsequent sup- pression of cFLIP [27]. Recently, we have documented that abrogation of SMURF and NEDD4 results in activation of ataxia-telangiectasia mutated which negatively regulates cFLIP $[28,29]$.

\section{MicroRNA: Mini Miracles - Friend or Foe?}

An overview of the current knowledge of microRNA (miRNA) function in prostate cancer will enable oncologists to envision future opportunities and challenges of this research field.

miRNAs have broader implications in terms of induction of apoptosis in neoplastic cells. miR-34a and miR$34 \mathrm{c}$ play an important role in AR-dependent p53-mediated apoptosis in prostate cancer $[16,17]$. miR-34a expression is reduced in p53-deficient cells; however, cells reconstituted for the $\mathrm{p} 53$ gene restored the expression of miR-34a [30]. p53 induces the expression of miR-34a which suppresses SIRT1, increasing p53 activity [31, 32].

In a similar way, miR-21 contributes to the resistance of prostate cancer cells to docetaxel, and targeting miR-21 may offer a promising therapeutic approach in sensitizing prostate cancer to docetaxel treatment $[33,34]$.

In prostate cancer, evidence has pointed towards the contribution of the androgen-dependent gene network to tumor growth. Murata et al. [35] identified androgen-responsive miRNAs and documented that miR-148a downregulates the expression of a tumor suppressor, cullinassociated and neddylation-dissociated 1 (CAND1), by binding to the 3 '-untranslated region of CAND1 messenger RNA.

On the other hand, some mitrons are tumor suppressors and are downregulated in tumor progression. One of the genes significantly upregulated by miR-145 overexpression is the proapoptotic gene TNFSF10. Therefore, modulation of miR-145 may be an important therapeutic approach for the management of prostate cancer as more detailed and clear in vitro studies of the expression profile of this mitron can be helpful for disease mitigation [36].

miR-8, miR-200c and miR-141 being antineoplastic act as potent inhibitors of Notch-induced overgrowth and tumor metastasis [37]. On a similar note, miR-125b and the miR-99 family members miR-99a, miR-99b and miR-100 are tumor suppressors. There is a remarkable downregulation of these mitrons in prostate cancer progression. On the other hand, restoration of these mitrons resulted in the reduction in expression of prostate-specific antigen. SMARCA5 and SMARCD1 and the growth regulatory kinase mTOR are triggered by the miR-99 family [38]. 
Fig. 2. An overview of miRNA processings and implications. NF- $\kappa \mathrm{B}=$ Nuclear factor$\kappa \mathrm{B} ; \mathrm{FSCN}=$ fascin homolog; $\mathrm{MnSOD}=$ manganese superoxide dismutase; GPX2 = glutathione peroxidase 2 ; $\operatorname{TrxR} 2=$ thioredoxin reductase 2 .

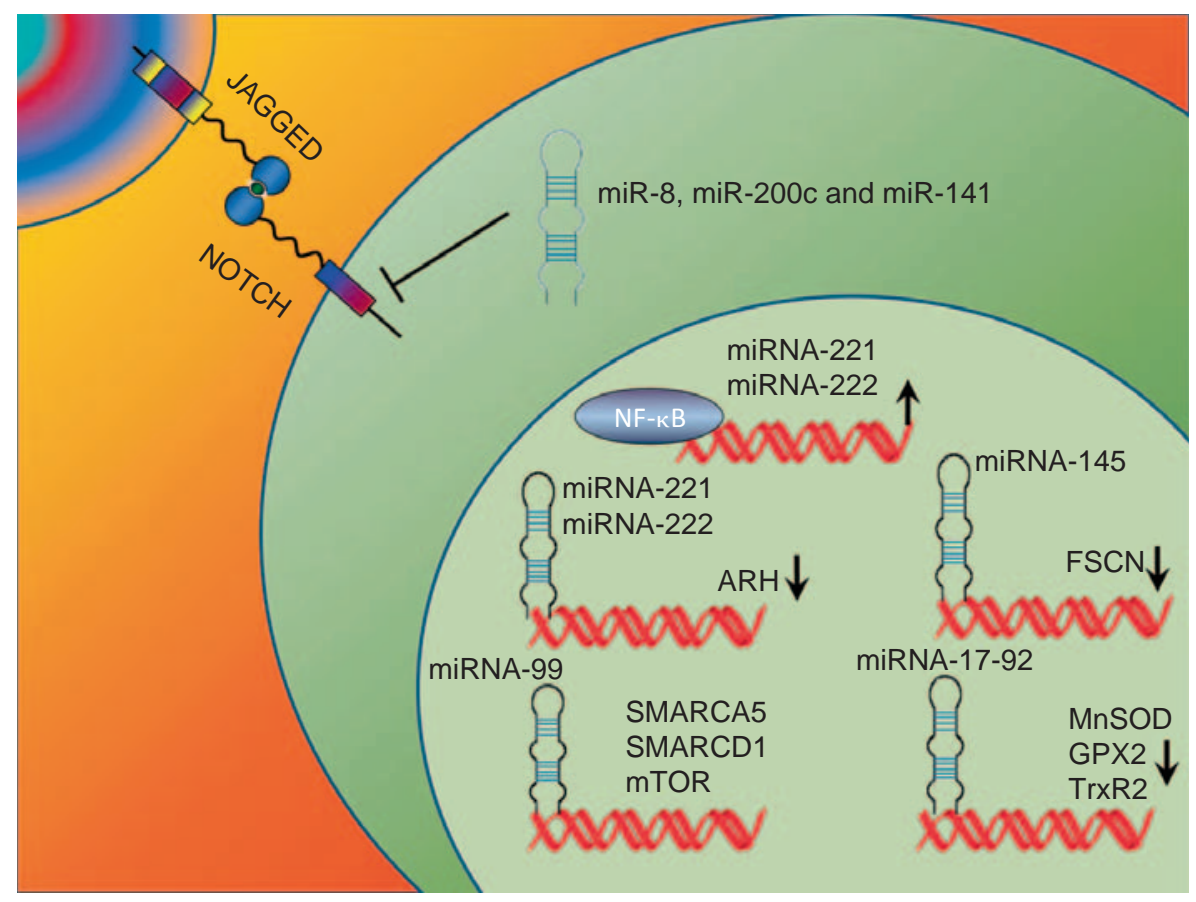

The miR-17-92 cluster has broader involvement in terms of suppression of mitochondrial antioxidant enzymes, such as manganese superoxide dismutase, glutathione peroxidase 2 and thioredoxin reductase 2 . It is documented by $\mathrm{Xu}$ et al. [39] that miR-17* binding sequences are located in the $3^{\prime}$-untranslated regions of these 3 target genes. Transient transfection of neoplastic cells with miR-143 and miR-203 resulted in regression of proliferation and invasive potential [40, 41] (fig. 2).

Existing polymorphisms in miRNAs and respective target sites underpin variant clinical outcomes in prostate cancer patients [42].

miR-221 and miR-222 are oncomirs which are engaged in the suppression of tumor suppressor genes. miR221 and miR-222 inhibitors caused significant induction of a tumor suppressor aplasia Ras homolog member I (ARHI). A direct interaction of miR-221 or miR-222 with a target site on the $3^{\prime}$-UTR of ARHI was confirmed by Chen et al. [14] in 2011. It is also worth mentioning that genistein upregulates ARHI by attenuating miR-221 and miR-222 in prostate cancer cells.

Mounting evidence indicates that some proteins are involved in the stimulation of mitrons. Nuclear factor- $\kappa \mathrm{B}$ triggers miR-221/222 expression in prostate cancer. Recently, Galardi et al. [43] identified two regions upstream of the miR-221/222 promoter which are bound by the nuclear factor- $\mathrm{\kappa B}$ subunit $\mathrm{p} 65$.
While drawing a parallel between advanced-stage patients and localized disease patients, levels of miR-21, miR-141 and miR-221 were significantly higher in advanced stages than in patients with localized disease [44]. It is also interesting to note that a relatively higher level of miR-100 is related to biochemical recurrence of localized prostate cancer in patients treated with radical prostatectomy [45].

Reconstituted cells for miR-145 displayed an inhibited cell proliferation, migration and invasion. This antineoplastic activity was modulated by a significantly decreased signal at two miR-145 target sites at the $3^{\prime}$-UTR of fascin homolog 1, suggestive of the fact that miR-145 negatively regulates fascin homolog 1 , an actin-bundling protein [46].

Keeping in view the crests and troughs between methylation and loss of imprinting, it is documented by Hulf et al. [47] that miR-205, miR-21 and miR-196b are epigenetically repressed, and miR-615 is epigenetically activated in prostate cancer cells.

miR-34a is a p53 target and was underexpressed in CD44(+) prostate cancer cells. CD44 knockdown was similar to miR-34a overexpression in retarding prostate cancer metastasis [48].

Phytonutrients stimulate the expression of tumor suppressors. Siddiqui et al. [49] observed a suppression of androgen-regulated miR-21 and upregulation of a tumor 
suppressor, miR-330, in tumors of mice treated with epigallocatechin gallate. miRNAs in tumor microenvironment act in a new network that reinforces tumor suppressor gene expression, reducing the expression of AR-mediated transcriptional activities and activators.

\section{Prostate Stem Cells: Same Ballpark, Different Players and Different Rules}

Cells within a tumor are structured and controlled in a hierarchical lineage relationship and portray differential tumorigenic potential, signifying that targeted therapeutics should converge upon rare cancer stem cells that maintain tumor malignancy. In the upcoming section, we will discuss the existing status of studies to identify cancer stem cells in human prostate cancer as well as in mouse models, with an emphasis on discussing different functional assays and relative hopes and pitfalls.

Rajasekhar et al. [50] identified a minor subset of stemlike human prostate tumor-initiating cells (TICs) that neither expressed AR nor prostate-specific antigen. These TICs have stem cell-like hallmark features and multipotency as verified by sphere formation in various in vitro experimentations and in vivo tumor initiation, respectively. The cells give a snapshot of an undifferentiated subtype of basal cells which might be purified from prostate tumors, coexpressing human pluripotent stem cell marker TRA-1-60 with CD151 and CD166. It is worth mentioning that such triple-marker-positive TICs restore the original parent tumor heterogeneity in serial xenotransplantations, underscoring a tumor cell hierarchy in carcinogenesis. It is also interesting to note that the CD44(+) cell population is presumed to have stem cell-like properties. In accordance with this assumption, Yu et al. [51] introduced these CD44(+) and high-activity aldehyde dehydrogenase-containing cells into severe combined immune-defi- cient mice to determine the corresponding tumorigenic capacities. The cells were able to reinforce tumorigenesis in the mice. Additionally, Yin et al. [52] isolated the cancer stem cell-like side population cells from the human prostate cancer cell line DU-145 by a flow cytometry-based side population technique. The research group was able to characterize various proteins upregulated in prostate cancer stem cells. Notably, arachidonate 12-lipoxygenase and ATP-binding cassette subfamily $\mathrm{G}$ member 2 are upregulated in prostate cancer stem cells. Lately, Rybak et al. [53] reported enrichment and characterization of spherepropagating cells with stem-like properties from DU-145 prostate cancer cells in a defined serum-free medium.

Another important breakthrough in prostate cancer stem cell initiation was given by Chang et al. [54] who stated that Sonic hedgehog signal transduction is involved in transforming normal prostate basal/stem cells into prostate cancer stem cells. Similarly, Nodal, a TGF$\beta$-like growth factor, maintains the pluripotency of embryonic stem cells. Nodal mediated proliferation and cellular migration via ALK4 and ActRII/ActRIIB receptors and Smad $2 / 3$ phosphorylation. It clearly indicated that Nodal-mediated signaling cascade is enhanced in cellular transformation [55].

\section{Conclusion and Future Directions}

Prostate cancer exempts a large number of therapeutic tools, yet many leading methodologies stand in queue. Being a multifactorial anomaly, prostate cancer overtakes a complex of interrelated molecules. miRNAs and stem cells occupy the top slot. All these factors are substantially intertwined, so mono-oriented targeting is of no use. Making up with these new parameters may give a sharp optimistic twist to future interventions in prostate therapeutics.
References
1 Farooqi AA, Bhatti S: Fusion transcripts: hopes and pitfalls in tranquilizing the trouble mongers in prostate cancer. J Exp Integr Med, in press.

2 Clark JP, Cooper CS: ETS gene fusions in prostate cancer. Nat Rev Urol 2009;6:429439.

3 Li Y, Alsagabi M, Fan D, Bova GS, Tewfik $\mathrm{AH}$, Dehm SM: Intragenic rearrangement and altered RNA splicing of the androgen receptor in a cell-based model of prostate cancer progression. Cancer Res 2011;71:21082117.
4 Dehm SM, Schmidt LJ, Heemers HV, Vessella RL, Tindall DJ: Splicing of a novel androgen receptor exon generates a constitutively active androgen receptor that mediates prostate cancer therapy resistance. Cancer Res 2008;68:5469-5477.

5 Marcias G, Erdmann E, Lapouge G, Siebert C, Barthélémy P, Duclos B, Bergerat JP, Céraline J, Kurtz JE: Identification of novel truncated androgen receptor (AR) mutants including unreported pre-mRNA splicing variants in the 22Rv1 hormone-refractory prostate cancer (PCa) cell line. Hum Mutat 2010;31:74-80. 
-6 Guo Z, Yang X, Sun F, Jiang R, Linn DE, Chen H, Chen H, Kong X, Melamed J, Tepper CG, Kung HJ, Brodie AM, Edwards J, Qiu Y: A novel androgen receptor splice variant is up-regulated during prostate cancer progression and promotes androgen depletionresistant growth. Cancer Res 2009;69:23052313.

7 Sun S, Sprenger CC, Vessella RL, Haugk K, Soriano K, Mostaghel EA, Page ST, Coleman IM, Nguyen HM, Sun H, Nelson PS, Plymate SR: Castration resistance in human prostate cancer is conferred by a frequently occurring androgen receptor splice variant. J Clin Invest 2010;120:2715-2730.

$>8$ Vainio P, Gupta S, Ketola K, Mirtti T, Mpindi JP, Kohonen P, Fey V, Perälä M, Smit F, Verhaegh G, Schalken J, Alanen KA, Kallioniemi O, Iljin K: Arachidonic acid pathway members PLA2G7, HPGD, EPHX2, and CYP4F8 identified as putative novel therapeutic targets in prostate cancer. Am J Pathol 2011;178:525-536.

-9 Kim SD, Park RY, Kim YR, Kim IJ, Kang TW, Nam KI, Ahn KY, Bae CS, Kim BY, Park SS, Jung C: HOXB13 is co-localized with androgen receptor to suppress androgen-stimulated prostate-specific antigen expression. Anat Cell Biol 2010;43:284-293.

10 Draker R, Sarcinella E, Cheung P: USP10 deubiquitylates the histone variant $\mathrm{H} 2 \mathrm{~A} . \mathrm{Z}$ and both are required for androgen receptormediated gene activation. Nucleic Acids Res 2011, Epub ahead of print.

$\checkmark 11$ Thomas C, Zoubeidi A, Kuruma H, Fazli L, Lamoureux F, Beraldi E, Monia BP, MacLeod AR, Thüroff JW, Gleave ME: Transcription factor Stat5 knockdown enhances androgen receptor degradation and delays castrationresistant prostate cancer progression in vivo. Mol Cancer Ther 2011;10:347-359.

12 Yang Y, Tse AK, Li P, Ma Q, Xiang S, Nicosia SV, Seto E, Zhang X, Bai W: Inhibition of androgen receptor activity by histone deacetylase 4 through receptor SUMOylation. Oncogene 2011, Epub ahead of print.

$\checkmark 13$ Hu XD, Meng QH, Xu JY, Jiao Y, Ge CM, Jacob A, Wang P, Rosen EM, Fan S: BTG2 is an LXXLL-dependent co-repressor for androgen receptor transcriptional activity. Biochem Biophys Res Commun 2011;404:903909.

14 Chen G, Goto Y, Sakamoto R, Tanaka K, Matsubara E, Nakamura M, Zheng H, Lu J, Takayanagi R, Nomura M: GLI1, a crucial mediator of Sonic hedgehog signaling in prostate cancer, functions as a negative modulator for androgen receptor. Biochem Biophys Res Commun 2011;404:809-815.

-15 Tan SS, Ahmad I, Bennett HL, Singh L, Nixon C, Seywright M, Barnetson RJ, Edwards J, Leung HY: GRP78 up-regulation is associated with androgen receptor status, Hsp70Hsp90 client proteins and castrate-resistant prostate cancer. J Pathol 2011;223:81-87.
6 Mashima T, Okabe S, Seimiya H: Pharmacological targeting of constitutively active truncated androgen receptor by nigericin and suppression of hormone-refractory prostate cancer cell growth. Mol Pharmacol 2010;78:846-854.

17 Rokhlin OW, Taghiyev AF, Bayer KU, Bumcrot D, Koteliansk VE, Glover RA, Cohen MB: Calcium/calmodulin-dependent kinase II plays an important role in prostate cancer cell survival. Cancer Biol Ther 2007;6:732742.

18 Rokhlin OW, Scheinker VS, Taghiyev AF, Bumcrot D, Glover RA, Cohen MB: MicroRNA-34 mediates AR-dependent p53-induced apoptosis in prostate cancer. Cancer Biol Ther 2008;7:1288-1296.

19 Park SY, Lee YH, Choi KC, Seong AR, Choi HK, Lee OH, Hwang HJ, Yoon HG: Grape seed extract regulates androgen receptormediated transcription in prostate cancer cells through potent anti-histone acetyltransferase activity. J Med Food 2011;14:9 16.

20 Choi KC, Park S, Lim BJ, Seong AR, Lee YH, Shiota M, Yokomizo A, Naito S, Na Y, Yoon HG: Procyanidin B3, an inhibitor of histone acetyltransferase, enhances the action of antagonist for prostate cancer cells via inhibition of p300-dependent acetylation of androgen receptor. Biochem J 2010;433. 235-244.

-21 Kang BH, Tavecchio M, Goel HL, Hsieh CC, Garlick DS, Raskett CM, Lian JB, Stein GS Languino LR, Altieri DC: Targeted inhibition of mitochondrial Hsp90 suppresses localised and metastatic prostate cancer growth in a genetic mouse model of disease. Br J Cancer 2011;104:629-634.

-22 Scher HI, Beer TM, Higano CS, Anand A, Taplin ME, Efstathiou E, Rathkopf D, Shelkey J, Yu EY, Alumkal J, Hung D, Hirmand M, Seely L, Morris MJ, Danila DC Humm J, Larson S, Fleisher M, Sawyers CL, Prostate Cancer Foundation/Department of Defense Prostate Cancer Clinical Trials Consortium: Antitumour activity of MDV3100 in castration-resistant prostate cancer: a phase 1-2 study. Lancet 2010;375: 1437-1446.

23 Rokhlin OW, Guseva NV, Taghiyev AF, Glover RA, Cohen MB: KN-93 inhibits androgen receptor activity and induces cell death irrespective of p53 and Akt status in prostate cancer. Cancer Biol Ther 2010;9: 224-235.

24 Siddiqui IA, Malik A, Adhami VM, Asim M, Hafeez BB, Sarfaraz S, Mukhtar H: Green tea polyphenol EGCG sensitizes human prostate carcinoma LNCaP cells to TRAIL-mediated apoptosis and synergistically inhibits biomarkers associated with angiogenesis and metastasis. Oncogene 2008;27:20552063.
25 Shankar S, Ganapathy S, Srivastava RK: Sulforaphane enhances the therapeutic potential of TRAIL in prostate cancer orthotopic model through regulation of apoptosis, metastasis, and angiogenesis. Clin Cancer Res 2008; 14:6855-6866.

26 Andrzejewski T, Deeb D, Gao X, Danyluk A, Arbab AS, Dulchavsky SA, Gautam SC: Therapeutic efficacy of curcumin/TRAIL combination regimen for hormone-refractory prostate cancer. Oncol Res 2008;17:257267.

27 Farooqi AA, Fayyaz S, Bhatti S, Ismail M, Mansoor Q: Towards TRAIL to silencing of SMURF and NEDD4: FLIP is flopped. J Exp Integr Med 2011;1:111-116.

$>28$ Farooqi AA, Mansoor Q, Rana A, Mashhadi TM, Imran M, Naqi SA, Rehman Z, Bhatti S: SMURF and NEDD4 interference offers therapeutic potential in chaperoning genome integrity. J Exp Integr Med 2011;1:4350.

29 Stagni V, Mingardi M, Santini S, Giaccari D, Barilà D: ATM kinase activity modulates cFLIP protein levels: potential interplay between DNA damage signalling and TRAILinduced apoptosis. Carcinogenesis 2010;31: 1956-1963.

30 Fujita Y, Kojima K, Hamada N, Ohhashi R, Akao Y, Nozawa Y, Deguchi T, Ito M: Effects of miR-34a on cell growth and chemoresistance in prostate cancer PC 3 cells. Biochem Biophys Res Commun 2008;377:114-119.

-31 Yamakuchi M, Ferlito M, Lowenstein CJ: miR-34a repression of SIRT1 regulates apoptosis. Proc Natl Acad Sci USA 2008;105: 13421-13426.

-32 Yamakuchi M, Lowenstein CJ: miR-34, SIRT1 and p53: the feedback loop. Cell Cycle 2009;8:712-715.

33 Zhang HL, Yang LF, Zhu Y, Yao XD, Zhang SL, Dai B, Zhu YP, Shen YJ, Shi GH, Ye DW: Serum miRNA-21: elevated levels in patients with metastatic hormone-refractory prostate cancer and potential predictive factor for the efficacy of docetaxel-based chemotherapy. Prostate 2011;71:326-331.

34 Shi GH, Ye DW, Yao XD, Zhang SL, Dai B, Zhang HL, Shen YJ, Zhu Y, Zhu YP, Xiao WJ, Ma CG: Involvement of microRNA-21 in mediating chemo-resistance to docetaxel in androgen-independent prostate cancer PC3 cells. Acta Pharmacol Sin 2010;31:867-873.

-35 Murata T, Takayama K, Katayama S, Urano T, Horie-Inoue K, Ikeda K, Takahashi S, Kawazu C, Hasegawa A, Ouchi Y, Homma Y, Hayashizaki Y, Inoue S: miR-148a is an androgen-responsive microRNA that promotes LNCaP prostate cell growth by repressing its target CAND1 expression. Prostate Cancer Prostatic Dis 2010;13:356361.

>36 Zaman MS, Chen Y, Deng G, Shahryari V, Suh SO, Saini S, Majid S, Liu J, Khatri G, Tanaka Y, Dahiya R: The functional significance of microRNA-145 in prostate cancer. Br J Cancer 2010;103:256-264. 
>37 Vallejo DM, Caparros E, Dominguez M: Targeting Notch signalling by the conserved miR-8/200 microRNA family in development and cancer cells. EMBO J 2011;30:756769.

-38 Sun D, Lee YS, Malhotra A, Kim HK, Matecic M, Evans C, Jensen RV, Moskaluk CA, Dutta A: miR-99 family of microRNAs suppresses the expression of prostate-specific antigen and prostate cancer cell proliferation. Cancer Res 2011;71:1313-1324.

-39 Xu Y, Fang F, Zhang J, Josson S, St Clair WH, St Clair DK: miR-17* suppresses tumorigenicity of prostate cancer by inhibiting mitochondrial antioxidant enzymes. PLoS One 2010;5:e14356.

-40 Xu B, Niu X, Zhang X, Tao J, Wu D, Wang Z, Li P, Zhang W, Wu H, Feng N, Wang Z, Hua L, Wang X: miR-143 decreases prostate cancer cells proliferation and migration and enhances their sensitivity to docetaxel through suppression of KRAS. Mol Cell Biochem 2011;350:207-213.

41 Saini S, Majid S, Yamamura S, Tabatabai ZL, Suh SO, Shahryari V, Chen Y, Deng G, Tanaka Y, Dahiya R: Regulatory role of miR-203 in prostate cancer progression and metastasis. Clin Cancer Res 2010, Epub ahead of print.

42 Bao BY, Pao JB, Huang CN, Pu YS, Chang TY, Lan YH, Lu TL, Lee HZ, Juang SH, Chen LM, Hsieh CJ, Huang SP: Polymorphisms inside microRNAs and microRNA target sites predict clinical outcomes in prostate cancer patients receiving androgen-deprivation therapy. Clin Cancer Res 2011;17:928936.
43 Galardi S, Mercatelli N, Farace MG, Ciafrè $\mathrm{SA}$ : NF- $\kappa \mathrm{B}$ and $\mathrm{c}$-Jun induce the expression of the oncogenic miR-221 and miR-222 in prostate carcinoma and glioblastoma cells. Nucleic Acids Res 2011, Epub ahead of print.

44 Yaman Agaoglu F, Kovancilar M, Dizdar Y, Darendeliler E, Holdenrieder S, Dalay N, Gezer U: Investigation of miR-21, miR-141, and miR-221 in blood circulation of patients with prostate cancer. Tumor Biol 2011, Epub ahead of print.

45 Leite KR, Tomiyama A, Reis ST, Sousa-Canavez JM, Sañudo A, Dall'Oglio MF, Camara-Lopes LH, Srougi M: MicroRNA-100 expression is independently related to biochemical recurrence of prostate cancer. J Urol 2011;185:1118-1122.

46 Fuse M, Nohata N, Kojima S, Sakamoto S Chiyomaru T, Kawakami K, Enokida H, Nakagawa M, Naya Y, Ichikawa T, Seki N: Restoration of miR-145 expression suppresses cell proliferation, migration and invasion in prostate cancer by targeting FSCN1. Int J Oncol 2011;38:1093-1101.

47 Hulf T, Sibbritt T, Wiklund ED, Bert S, Strbenac D, Statham AL, Robinson MD Clark SJ: Discovery pipeline for epigenetically deregulated miRNAs in cancer: integration of primary miRNA transcription. BMC Genomics 2011;12:54

48 Liu C, Kelnar K, Liu B, Chen X, CalhounDavis T, Li H, Patrawala L, Yan H, Jeter C, Honorio S, Wiggins JF, Bader AG, Fagin R, Brown D, Tang DG: The microRNA miR-34a inhibits prostate cancer stem cells and metastasis by directly repressing CD44. Nat Med 2011;17:211-215.
49 Siddiqui IA, Asim M, Hafeez BB, Adhami VM, Tarapore RS, Mukhtar H: Green tea polyphenol EGCG blunts androgen receptor function in prostate cancer. FASEB J 2011;25: 1198-1207.

50 Rajasekhar VK, Studer L, Gerald W, Socci ND, Scher HI: Tumour-initiating stem-like cells in human prostate cancer exhibit increased NF- $\kappa \mathrm{B}$ signalling. Nat Commun 2011;2:162

51 Yu C, Yao Z, Dai J, Zhang H, Escara-Wilke J, Zhang X, Keller ET: ALDH activity indicates increased tumorigenic cells, but not cancer stem cells, in prostate cancer cell lines. In Vivo 2011;25:69-76.

52 Yin B, Yang Y, Zhao Z, Zeng Y, Mooney SM, Li M, Xu X, Song Y, Wu B, Yang Z: Arachidonate 12-lipoxygenase may serve as a potential marker and therapeutic target for prostate cancer stem cells. Int J Oncol 2011; 38:1041-1046.

53 Rybak AP, He L, Kapoor A, Cutz JC, Tang D: Characterization of sphere-propagating cells with stem-like properties from DU145 prostate cancer cells. Biochim Biophys Acta 2011, Epub ahead of print.

54 Chang HH, Chen BY, Wu CY, Tsao ZJ, Chen YY, Chang CP, Yang CR, Lin DP: Hedgehog overexpression leads to the formation of prostate cancer stem cells with metastatic property irrespective of androgen receptor expression in the mouse model. J Biomed Sci 2011;18:6

55 Vo BT, Khan SA: Expression of nodal and nodal receptors in prostate stem cells and prostate cancer cells: autocrine effects on cell proliferation and migration. Prostate 2011, Epub ahead of print. 